\title{
Rapid Reclamation and Degradation of Suaeda salsa Saltmarsh along Coastal China's Northern Yellow Sea
}

\author{
Jing Zhang ${ }^{1,2,3 \oplus \text {, Yan Zhang }}{ }^{1}$, Huw Lloyd ${ }^{4}$, Zhengwang Zhang ${ }^{5}$ and Donglai Li ${ }^{1, *}$ \\ 1 Provincial Key Laboratory of Animal Resource and Epidemic Disease Prevention, College of Life Sciences, \\ Liaoning University, Shenyang 110036, China; jingzhangcug@yeah.net (J.Z.); 13842652675@163.com (Y.Z.) \\ 2 State Key Laboratory of Urban and Regional Ecology, Research Center for Eco-Environmental Sciences, \\ Chinese Academy of Sciences, Beijing 100085, China \\ 3 University of Chinese Academy of Sciences, Beijing 100049, China \\ 4 Ecology and Environment Research Centre, Department of Natural Sciences, \\ Manchester Metropolitan University, Chester Street, Manchester M1 5GD, UK; H.Lloyd@mmu.ac.uk \\ 5 Ministry of Education Key Laboratory for Biodiversity Science and Ecological Engineering, \\ College of Life Sciences, Beijing Normal University, Beijing 100875, China; zzw@bnu.edu.cn \\ * Correspondence: lidonglai@lnu.edu.cn
}

check for updates

Citation: Zhang, J.; Zhang, Y.; Lloyd, H.; Zhang, Z.; Li, D. Rapid Reclamation and Degradation of Suaeda salsa Saltmarsh along Coastal China's Northern Yellow Sea. Land 2021, 10, 835. https://doi.org/ 10.3390/land10080835

Academic Editors:

Alexandru-Ionuţ Petrişor,

Adrian Ursu and

Ilinca-Valentina Stoica

Received: 20 July 2021

Accepted: 5 August 2021

Published: 9 August 2021

Publisher's Note: MDPI stays neutral with regard to jurisdictional claims in published maps and institutional affiliations.

Copyright: (c) 2021 by the authors. Licensee MDPI, Basel, Switzerland. This article is an open access article distributed under the terms and conditions of the Creative Commons Attribution (CC BY) license (https:// creativecommons.org/licenses/by/ $4.0 /)$.

\begin{abstract}
Suaeda salsa saltmarshes are an important coastal wetland habitat of China's northern Yellow Sea, which plays a critical role in sequestering carbon (blue carbon), protecting shorelines, maintaining biodiversity, and has substantial economic value (e.g., ecotourism). However, the area of $S$. salsa has been rapidly declining due to several different threats from reclamation and invasive species that impact its natural succession. Here, we map the changes in the distribution of the $S$. salsa saltmarshes along the northern Yellow Sea of China (NYSC) at 5-year intervals by applying the supervised maximum likelihood method to analyze Landsat images from 1988 to 2018 and investigate the potential impact of three important factors on habitat change by analyzing the temporal changes in S. salsa saltmarshes with other land covers. S. salsa saltmarsh areas have decreased by $63 \%$ $\left(264 \mathrm{~km}^{2}\right.$ ha to $\left.99 \mathrm{~km}^{2}\right)$, and the average loss of $S$. salsa saltmarshes was $5.5 \mathrm{~km}^{2} /$ year along the NYSC over the past three decades. There have been many dramatic declines in the two main distribution areas of $S$. salsa saltmarshes with a 77\% loss of habitat area in Liaodong Bay (from $112 \mathrm{~km}^{2}$ to $26 \mathrm{~km}^{2}$ ) and a $52 \%$ loss in the Yellow River Delta wetland-Guangli-Zhima estuarine wetland (from $137 \mathrm{~km}^{2}$ to $65 \mathrm{~km}^{2}$ ). Land reclamation is the most important impact factor in the loss of S. salsa saltmarshes, while there have been limited effects of natural succession and smooth cordgrass (Spartina alterniflora) invasion. In light of the important ecological services and economic value of the $S$. salsa habitat, emergency conservation actions (e.g., habitat restoration, strictly supervision) are needed to limit the rapid habitat loss, which should include the immediate cessation of extensive land reclamation along the NYSC.
\end{abstract}

Keywords: Suaeda salsa saltmarsh; land cover change; land reclamation; mudflat; Spartina alterniflora; Yellow Sea

\section{Introduction}

Coastal wetlands, which are composed by multiple natural landscapes connecting mainland and oceanic ecosystems, provide hugely significant ecological services (e.g., buffering ocean storms [1], shoreline protection against rising sea-levels, and maintaining biodiversity [2]) and have critical economic value from the contribution of their vast marine biological resources [3]. However, in recent decades, coastal wetlands have been under intensive pressure worldwide from land reclamation [4,5], reduced stream discharge and sediment fluxes from rivers [4,6], erosion, and sea-level rise [7]. Coastal wetland reclamation by seawall construction and other industrial and aquaculture land uses are the primary drivers for coastal wetland loss, resulting in a $16 \%$ loss of coastal tidal 
flats globally from 1984 to 2016 [5]. Reclamation has also indirectly negatively impacted local wetland ecosystems through soil compaction [8], heavy mental contamination, oil pollution, and biodiversity loss [9].

As one of the fifty largest marine ecosystems worldwide [10], the Yellow Sea, located in northeastern Asia, supports an estimated USD 30 billion in ecosystem services and approximately 60 million people across urban, industrial, agricultural and fishery sectors per year [11]. Given the variety of coastal wetland landscapes and the richness of marine benthic invertebrate resources, the Yellow Sea also supports more than 200 species of migratory waterbirds during stopovers and the breeding season along the East AsianAustralia Flyway [12,13]. Consequently, numerous protected areas and Ramsar sites have been established along the coast of the Yellow Sea [14], including the Yancheng National Nature Reserve, which is located near the southern Yellow Sea and is listed as the UNESCO World Heritage site [15]. The unprecedented urban, industrial, and agricultural land reclamation has however, resulted in a loss of $65 \%$ of tidal flats during the past five decades [16], increasing the vulnerability of local communities to cope with extreme weather events, especially with predicted climate warming and sea level rise. The reclamation of China's coastal wetlands is estimated to have caused a loss of ecosystem services and internationally shared biodiversity $[2,17]$. To improve the protection level for coastal wetlands and to provide strict controls for reclamation management, in 2018, the State Council of the People's Republic of China announced a respite to claiming coastal wetland for creating extra land, particularly for the more ecologically sensitive coastal wetlands distributed in the northern Yellow Sea of China (http://www.mnr.gov.cn/gk/ tzgg/201807/t20180726_2187020.html; accessed on 1 August 2021).

Tidal mudflats are the dominant coastal wetland habitat in the Yellow Sea region and are among the most extensive coastal wetland habitats globally $[16,18]$. These mudflats nourish countless macro-benthic invertebrates and are consequently used by millions of migratory waterbirds, including globally threatenrd species (e.g., Spoon-billed Sandpiper (Calidris pygmaea) [19], Bar-tailed Godwit (Limosa lappnica), and Great Knot (C. tenuirostris) [20]) for feeding but are also used by millions of people for clam production $[12,13,21]$. Suaeda salsa saltmarshes, which are distributed in the upper tidal region, represents another important wetland landscape component in the northern Yellow Sea [8,22], serving as a key ecotourism destintion ("red beach tourism") and an economic driver in areas such as Liaodong Bay. As an indication of this, from 2016 to 2020, the local government has paid RMB 0.3 billion to restore $S$. salsa saltmarshes and other natural marine ecosystems in an effort to maintain the "red beach landscape" [8].

S. salsa saltmarshes also provide important ecosystem services, such as carbon sequestration("blue carbon"), shoreline protection, and biodiversity maintenance [23,24], and serves as an important foraging and resting habitat for endangered waterbirds that migrate along the EAAF, including the Red-crowned Crane (Grus japonensis) [25,26], the Far Eastern Curlew (Numenius madagascariensis), and the Great Knot [22,27]. However, S. salsa saltmarshes also face serious threats from reclamation, lower runoff of river discharge, uncontrolled tourist development, oil exploitation, invasive species, and sea-level rise [8,24]. Due to these threats, during 1997 to 2016, the S. salsa saltmarsh area on the Liao River Estuary has been dramatically reduced and heavily fragmented [6,24], with similar declines reported from the Yellow River Delta from 1970 to 2015 [28]. Furthermore, because of their proximity to the wetland landscape mosaic in the upper tidal flats, $S$. salsa saltmarshes are naturally exposed to more serious reclamation effects than other mudflats. This loss and fragmentation is also having detrimental impacts on the population of shorebirds that depend on the $S$. salsa saltmarshes. Despite these losses, there is still a surprising yet significant gap in our knowledge regarding the patterns of spatial-temporal variation of these coastal wetland habitats across the northern Yellow Sea over the past several decades, thereby limiting our conservation evidence base, which is necessary for creating viable and realistic $S$. salsa saltmarsh restoration strategies at the regional or/and national government level. 
In order to fill these gaps, we mapped the historic spatial-temporal distribution and more recent changes to $S$. salsa saltmarsh distribution along the northern Yellow Sea of China from 1988 to 2018 at intervals of five years and calculated the change in the S. salsa saltmarsh distribution change rates from the interpretation of Landsat long time-series images. Moreover, in order to understand the reclamation and degradation of $S$. salsa saltmarshes in this region, we analyzed the temporal transfer into and out of $S$. salsa saltmarshes with other land cover types.

\section{Materials and Methods}

\subsection{Study Site}

The northern Yellow Sea of China (NYSC) is a semi-closed shallow sea over the continental shelf of eastern Asia, with an average water depth of $26 \mathrm{~m}$ [29]. The NYSC extends from the Yalu River estuary $\left(40^{\circ} 59^{\prime} \mathrm{N}, 124^{\circ} 19^{\prime} \mathrm{E}\right)$ in the north to the Shandong Peninsula $\left(37^{\circ} 25^{\prime} \mathrm{N}, 122^{\circ} 41^{\prime} \mathrm{E}\right)$ in the south (Figure 1). The tides around this region are typically semidiurnal and diurnal in some places, ranging from 1.5 to $8 \mathrm{~m}$ but are approximately $2-4.6 \mathrm{~m}$. The main coastal types include both cliff and alluvial coasts along the NYSC. The cliff coast is distributed along the Liaodong and Shandong Peninsula with no saltmarsh habitat, with the remaining coast being alluvial coast mudflat nourished by material exchanged between river sediment and the ocean. In this study, only the alluvial coast was investigated. As a species of salt-related vegetation, $S$. salsa can grow on large areas of the upper tidal flat where it is influenced by the influx of freshwater from more than 30 rivers in this area $[29,30]$. This habitat can frequently be submerged and exposed during floods and ebb tides. In recent decades, smooth cordgrass (Spartina alterniflora) has invaded and become established in the $S$. salsa habitat along the south of the NYSC [31,32].

\subsection{Landsat Images and Pre-Processing to Analyze Land Cover Changes in NYSC}

We took the DESCR conceptual framework [33] as a basis for this work to identify the drivers, exchanges, state of the environment, consequences, and responses of land loss. We downloaded the Landsat-5 Thematic Map (1988-2008, 35 images) and the Landsat-8 Operational Land Imager (2013-2018, 18 images) remote sensing images from the United States Geological Survey website (USGS; https://earthexplorer.usgs.gov; accessed on 1 May 2020) and the Geospatial Data Cloud website (https:/ / www.gscloud.cn; accessed on 1 May 2020), respectively. The highest quality remote sensing images with $<2 \%$ cloud cover from mid-August to early November were selected because the spectral signatures of $S$. salsa and other vegetation (e.g., reed (Phragmites australis), smooth cordgrass, rice) are more similar to each other in other seasons (e.g., spring and summer) [6].

\subsection{Extracting S. salsa Saltmarsh Distribution Data}

A total of 63 images with seven periods $(1988,1993,1998,2003,2008,2013,2018)$ were selected and screened to quantify land cover change. Artificial shorelines are formed by many types of ground features, such as sea dikes, roads, aquaculture ponds, saltpans, and cliffs. Given their complex structures, we delineated the artificial shorelines through visual interpretation with 1988 images and defined reclamation as the change in the area between the artificial shorelines during successive periods. According to the shapefile of the artificial shorelines along the NYSC, we clipped all of the images after Radiometric Calibration and FLAASH atmospheric correction using ENVI 5.3. Given the typical red coloration and distribution along the upper tidal region along the NYSC, S. salsa was easily distinguished from the other eight land cover types that were able to be identified: mudflat, reed, bare land, water cover, farmland, smooth cordgrass, reclaimed land, and forest (Figure 2). Finally, the supervised maximum likelihood method and visual interpretation were used to describe the land cover changes according to the Regions of Interests (ROIs) that we marked on the RS images from 1988 to 2018. Overall, 498 S. salsa ROIs and 9476 ROIs of other land cover types were randomly selected as training samples. Furthermore, on account of the influence of small patches on statistical power and mapping, Majority 
Analysis was used to coalesce the results with other land covers. All of the interpretations of the RS images were performed with ENVI 5.3.

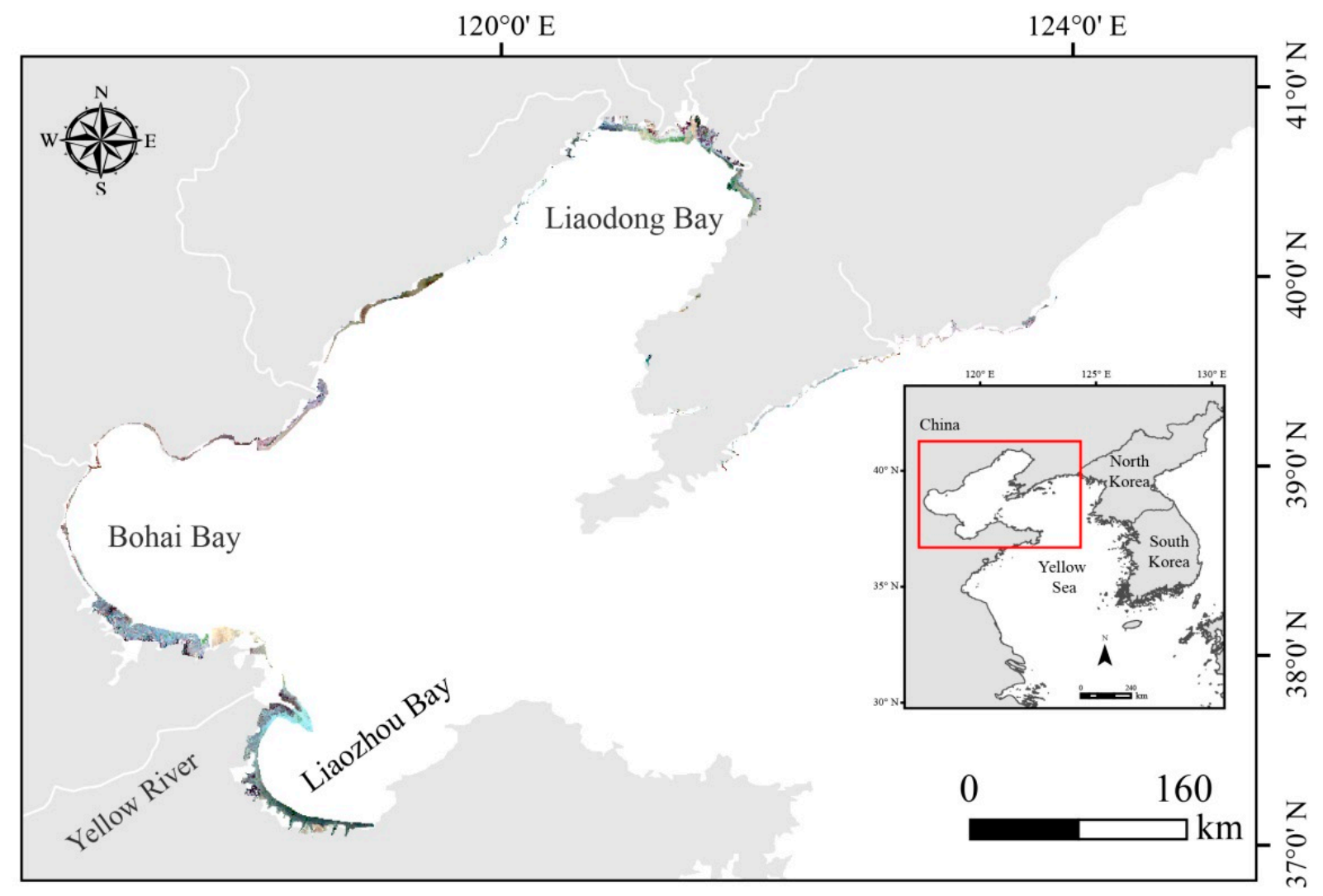

Figure 1. Location of the Northern Yellow Sea of China with subset RS images of 1988.

\subsection{Accuracy Assessment}

The accuracy of the final classification of $S$. salsa saltmarshes was assessed using geographical coordinates collected from field surveys in 2020 (125 and 2369 points in the $S$. salsa and other land cover types, respectively) and high spectral resolution images from 2013 to 2018 from Google Earth. A confusion matrix consisting of the overall accuracy and the kappa coefficient was created to measure the consistency between our classification and the validation samples. The classification for the estimated overall accuracy was $>89.95 \%$, and the kappa coefficient was 0.83 .

\subsection{Land Cover Change of S. salsa Saltmarsh}

We used Class Statistics to calculate the area of $S$. salsa vegetation and other land classifications along the NYSC coast in ENVI 5.3 software. To explore the temporal and spatial change of S. salsa saltmarshes from 1988 to 2018, Change Detection Statistics were used to calculate the area of land cover transferred into and out of $S$. salsa saltmarshes with reclamation area, mudflat, reed, smooth cordgrass, and other land cover types at five-year periods (1988-1993; 1993-1998; 1998-2003; 2003-2008; 2008-2013; 2013-2018). The average change rates of different land cover types were calculated by dividing the total change in area by the periods in which the changes occurred. Maps of S. salsa saltmarshes, reclamation, area and mudflats for all stages were overlaid into one shapefile;the temporal and spatial distribution maps of three land cover types from 1988 to 2018 were then drawn using ArcGIS 10.2 (ESRI, Inc., Redlands, CA, USA). 

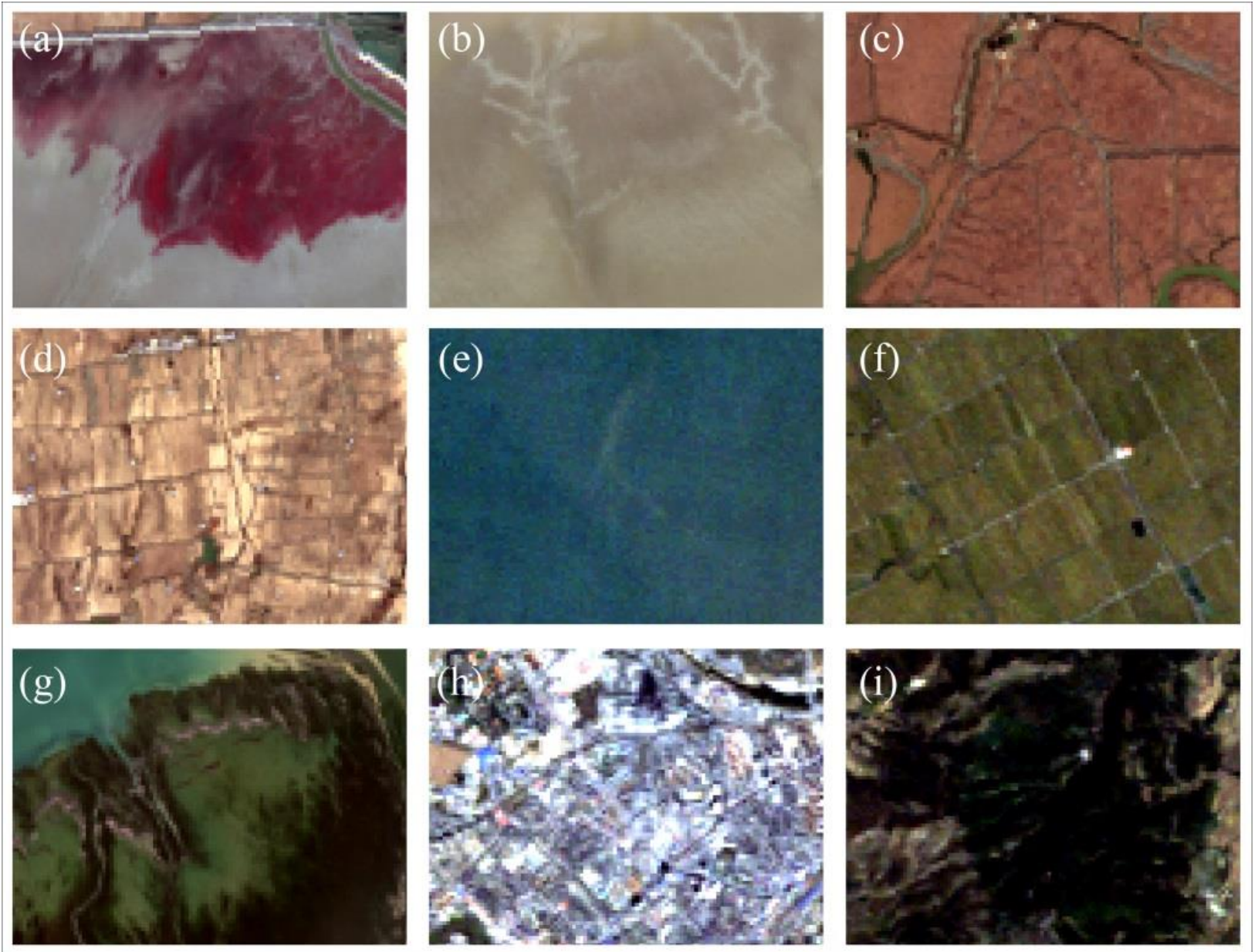

Figure 2. The nine different types of land cover in the Northern Yellow Sea of China: (a) S. salsa; (b) mudflat; (c) reed (Phragmites. australis); (d) bare land; (e) water cover; (f) farmland; (g) smooth cordgrass (Spartina alterniflora); (h) reclaimed land; (i) forest.

\section{Results}

\subsection{Temporal and Spatial Distribution of S. salsa Saltmarsh}

In 1988, the extent of the $S$. salsa habitat was estimated to be $263 \mathrm{~km}^{2}$ (Figure 3), it was and mainly distributed in the Liaodong Bay (Liaohe-Xiaolinghe estuarine wetland, $112 \mathrm{~km}^{2}$ ), the Yellow River Delta wetland, and the Guangli-Zhima estuarine wetland $\left(137 \mathrm{~km}^{2}\right)$ in northern Laizhou Bay. In addition, $6 \%$ of the $S$. salsa habitat was located in other estuarine wetlands with lower annual runoff (Figure 4). During the last three decades, the area composed of $S$. salsa saltmarshes dramatically decreased by $63 \%$, from $263 \mathrm{~km}^{2}$ to $99 \mathrm{~km}^{2}$, with an average loss rate of $5.5 \mathrm{~km}^{2} /$ year along the NYSC. There were two significant periods of change in the extent of $S$. salsa saltmarsh loss: the $S$. salsa saltmarsh area decreased dramatically by $55 \%$ from $263 \mathrm{~km}^{2}$ to $118 \mathrm{~km}^{2}$ from 1988 to 1993 and then further declined by 16\% from 1993 to 2018 although there were obvious increases detected in 1998 and 2008.

In the two core areas of $S$. salsa saltmarsh distribution, Liaodong Bay suffered the most dramatic decline, with a net loss of $77 \%$ from $112 \mathrm{~km}^{2}$ to $26 \mathrm{~km}^{2}$ (Figure 5), and in the Yellow River Delta and Guangli-Zhima estuarine wetlands, the $S$. salsa habitat decreased by $52 \%$, from $137 \mathrm{~km}^{2}$ to $65 \mathrm{~km}^{2}$ (Figure 6). From 1988 to 2018, the S. salsa saltmarsh area in Huludao city, Jinzhou City, Yingkou City, the eastern part of Panjing City, the Guangli-Zhima estuarine wetland, and $\mathrm{u}$ thepper tidal flat of Liaohekou National Nature Reserve almost disappeared entirely. However, the $S$. salsa saltmarsh area in the Yellow 
River Delta wetland where the Yellow National Nature Reserve is located experienced no significant change (Figures 5 and 6).

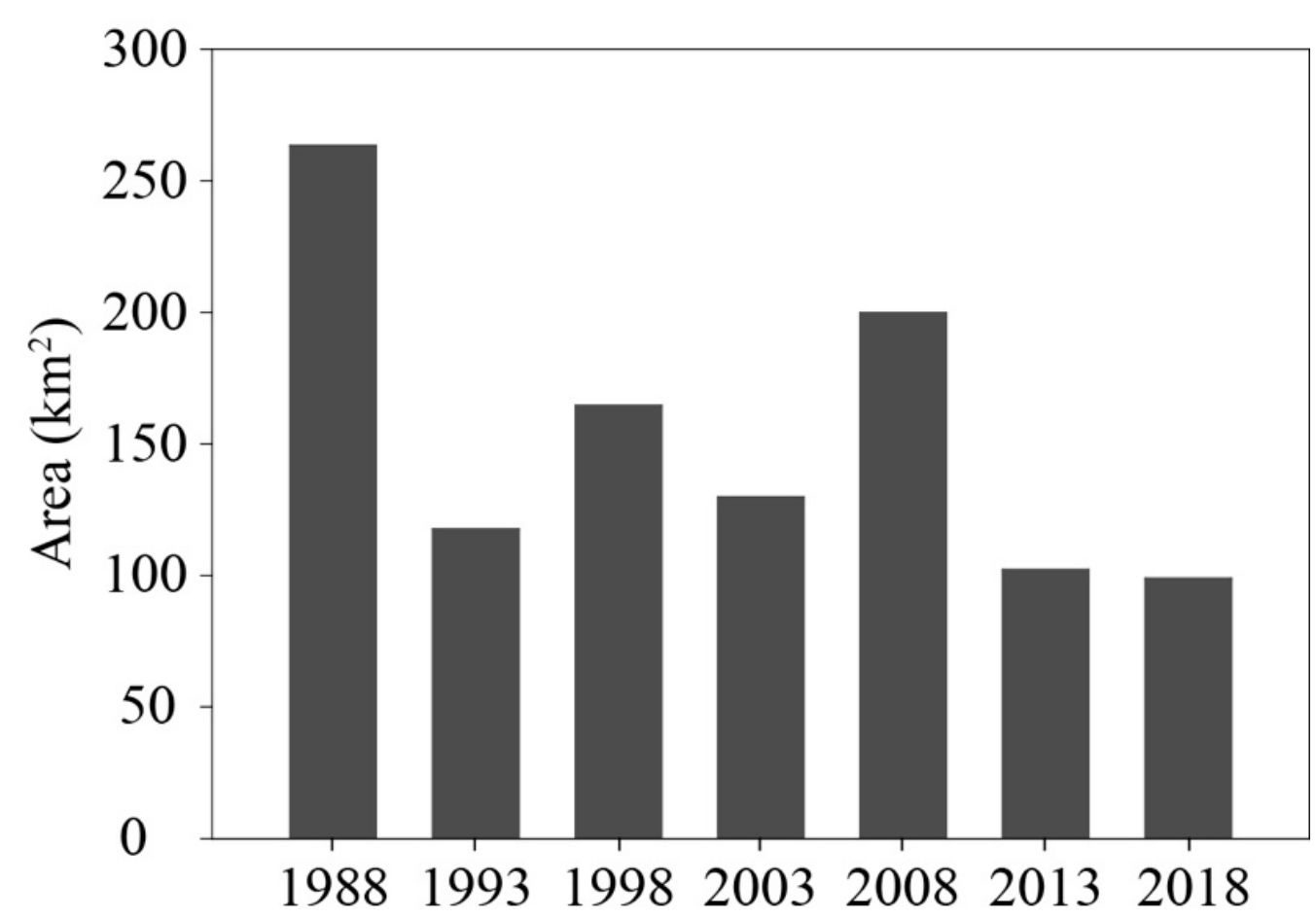

Figure 3. Total S. salsa saltmarsh area at different stages between 1988 and 2018 along the NYSC.

\subsection{Effects of Reclamation and Natural Succession on S. salsa Saltmarsh Dynamics}

Land reclamation was the main reason for the decline of the $S$. salsa saltmarsh areas and is responsible for a loss of $111 \mathrm{~km}^{2}$ of the whole NYSC region (Figures 4 and 7), corresponding to $78 \mathrm{~km}^{2}$ in Liaodong Bay (Figure 8) and $19 \mathrm{~km}^{2}$ in the Yellow River Delta and Guangli-Zhima estuarine wetlands (Figure 9). In turn, there was some degree of natural succession between the $S$. salsa saltmarsh and mudflat areas with the total net area of $3 \mathrm{~km}^{2}$ the $S$. salsa saltmarsh areas succeeding into mudflats from 1988 to 2018 . There were different patterns between regions, with $14 \mathrm{~km}^{2}$ of mudflat succeeding into $S$. salsa saltmarsh in Liaodong Bay and $35 \mathrm{~km}^{2}$ of $S$. salsa saltmarsh succeeding into mudflats in the Yellow River Delta and Guangli-Zhima estuarine wetlands. The highly invasive smooth cordgrass was first found in the Yellow River Delta wetland and the Guangli-Zhima estuarine wetlands $\left(19 \mathrm{~km}^{2}\right)$ and in the Tianjin Coastal wetland $\left(4 \mathrm{~km}^{2}\right)$ in 1993 and 1998, respectively. During the last several decades, only $1 \mathrm{~km}^{2} S$. salsa saltmarsh area was entirely lost to smooth cordgrass invasion, which mainly occupied the $S$. salsa saltmarsh area in the Yellow River Delta wetland and the Guangli-Zhima estuarine wetland $\left(0.49 \mathrm{~km}^{2}\right.$; Figure 9$)$.

\section{Discussion}

In this study, we first mapped the historical spatial-temporal distribution of S. salsa saltmarsh areas near the NYSC from 1988 to 2018 by using a long time-series of Landsat images, which revealed that Liaodong Bay and the Yellow River Delta wetland-GuangliZhima estuarine wetlands are the core distribution regions of $S$. salsa saltmarsh areas $(95 \%)$, which remains true to present day. Consistent with other findings on the loss of coastal wetlands, there has been an extensive loss of $S$. salsa saltmarsh areas on the coast of the NYSC during the past three decades, primarily driven by land reclamation $[4,16,24]$. During the past several decades, significant areas of coastal wetlands have been lost due to human reclamation and natural changes; for example, tidal flats have declined by $16.02 \%$ since 1984, and mangroves have decreased by $1 \%$ per year on average, whereas mudflat 
accretion has converted to erosion during the past decade because of the decline of coastal sediment supplied by the nearby rivers [4,5,34]. Notably, along the coast of the Yellow Sea, $49 \%$ of mudflat areas and 67\% of saltmarsh areas have been lost from 1984 to 2015 . Meanwhile, the land reclamation areas have increased by $7696 \mathrm{~km}^{2}$, which has resulted in the decrease of numerous waterbird stopover sites in this region [4]. Further declines are likely in the near future if the recent levels of reclamation continue.

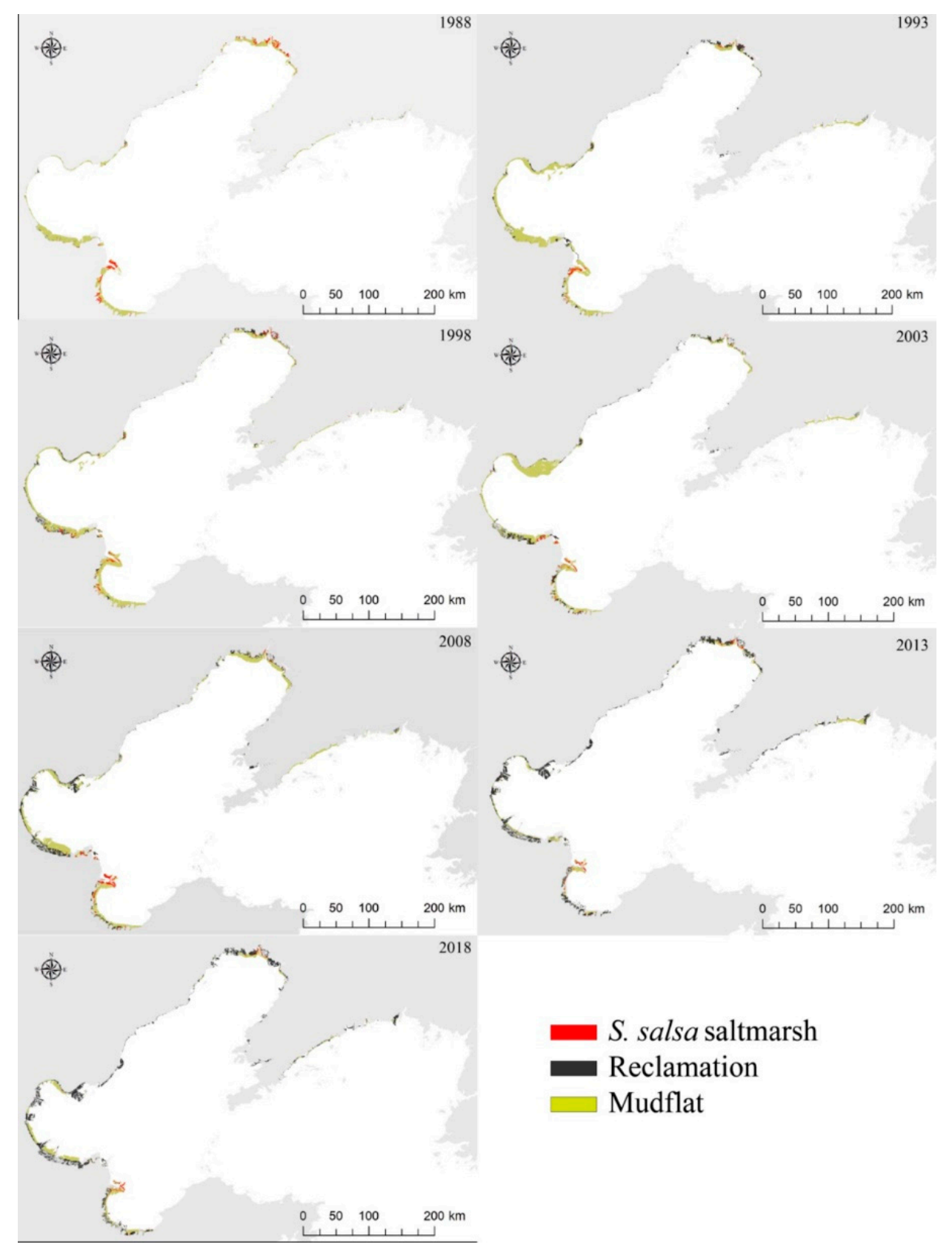

Figure 4. Maps showing the land cover change of the $S$. salsa saltmarsh area and mudflats and the reclaimed land along the NYSC between 1988 and 2018. 


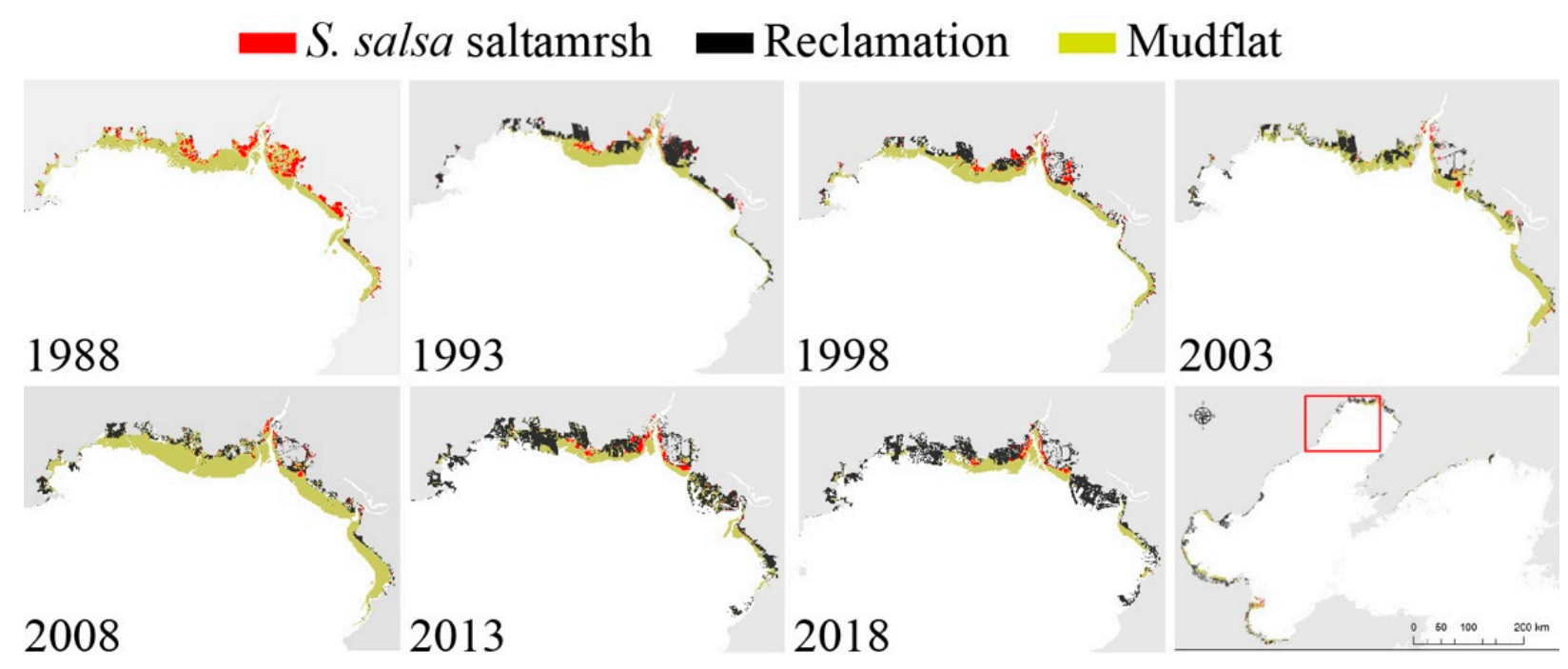

Figure 5. Maps showing the land cover change of S. salsa saltmarsh area and mudflats and the reclaimed land in Liaodong Bay between 1988 and 2018.

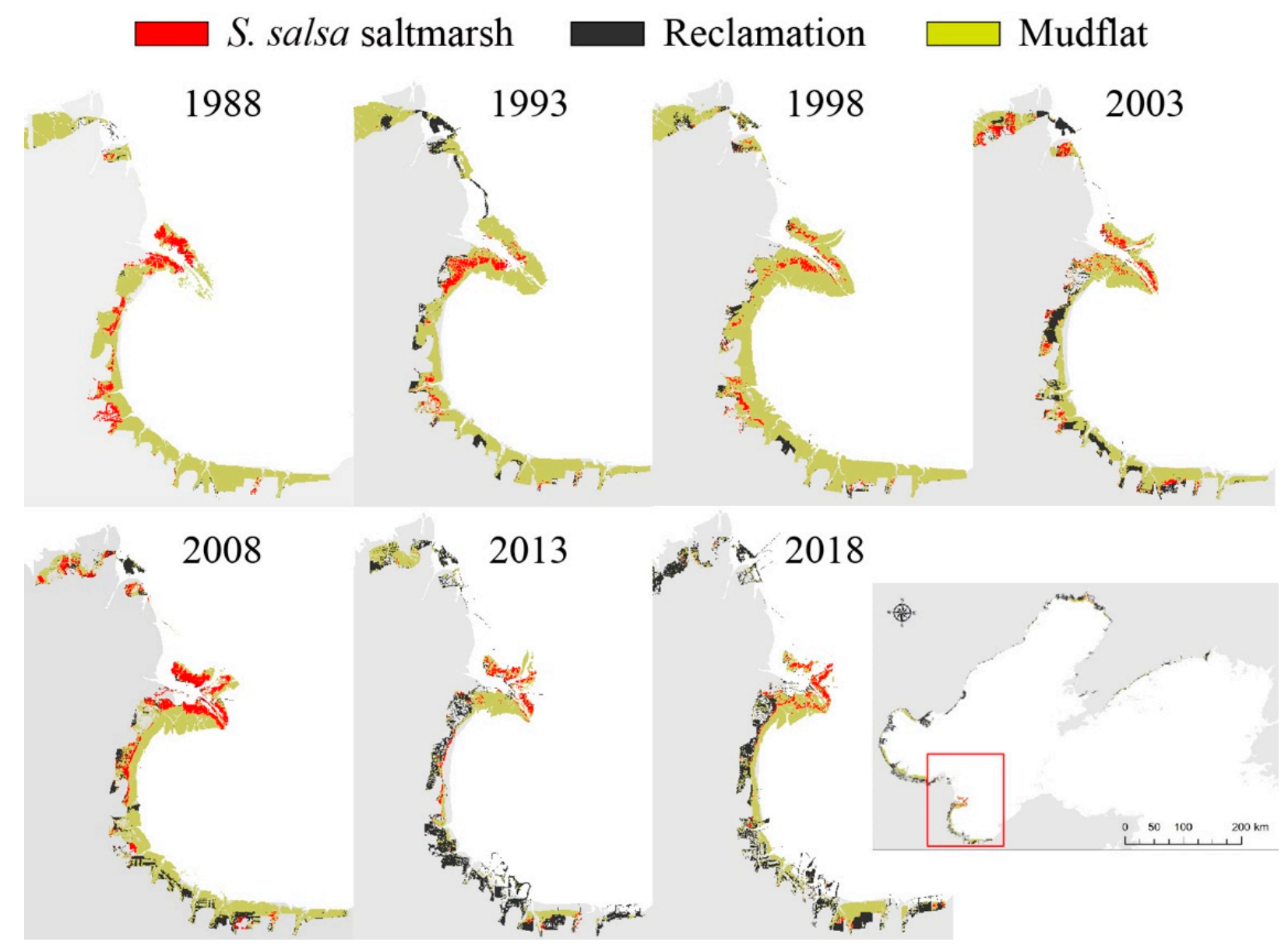

Figure 6. Maps showing the land cover change of $S$. salsa saltmarsh areas and mudflats and the reclaimed land in Yellow River Delta wetland and Guangli-Zhima estuarine wetland between 1988 and 2018. 


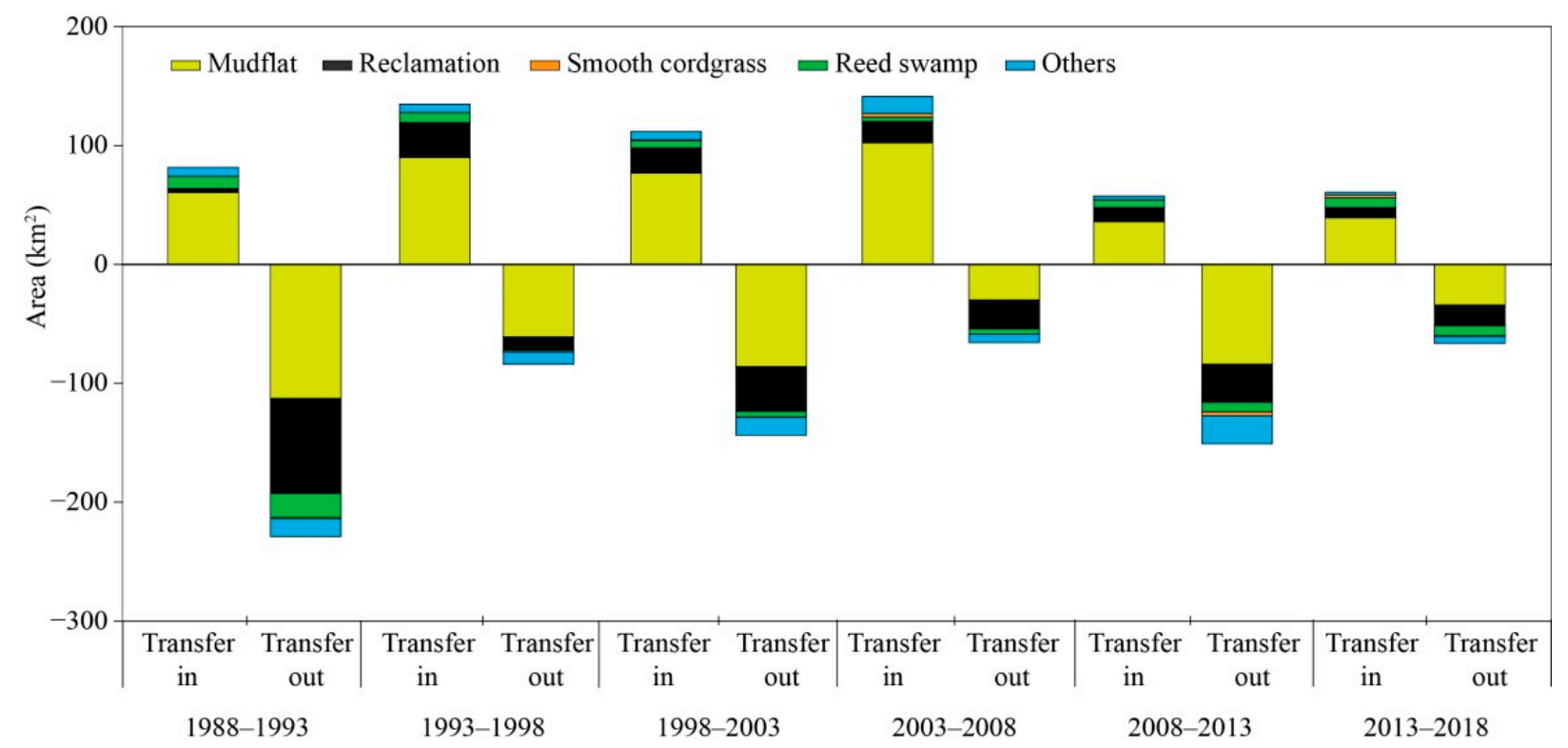

Figure 7. Land change between S. salsa saltmarsh area and other habitats near the NYSC from 1988 to 2018.

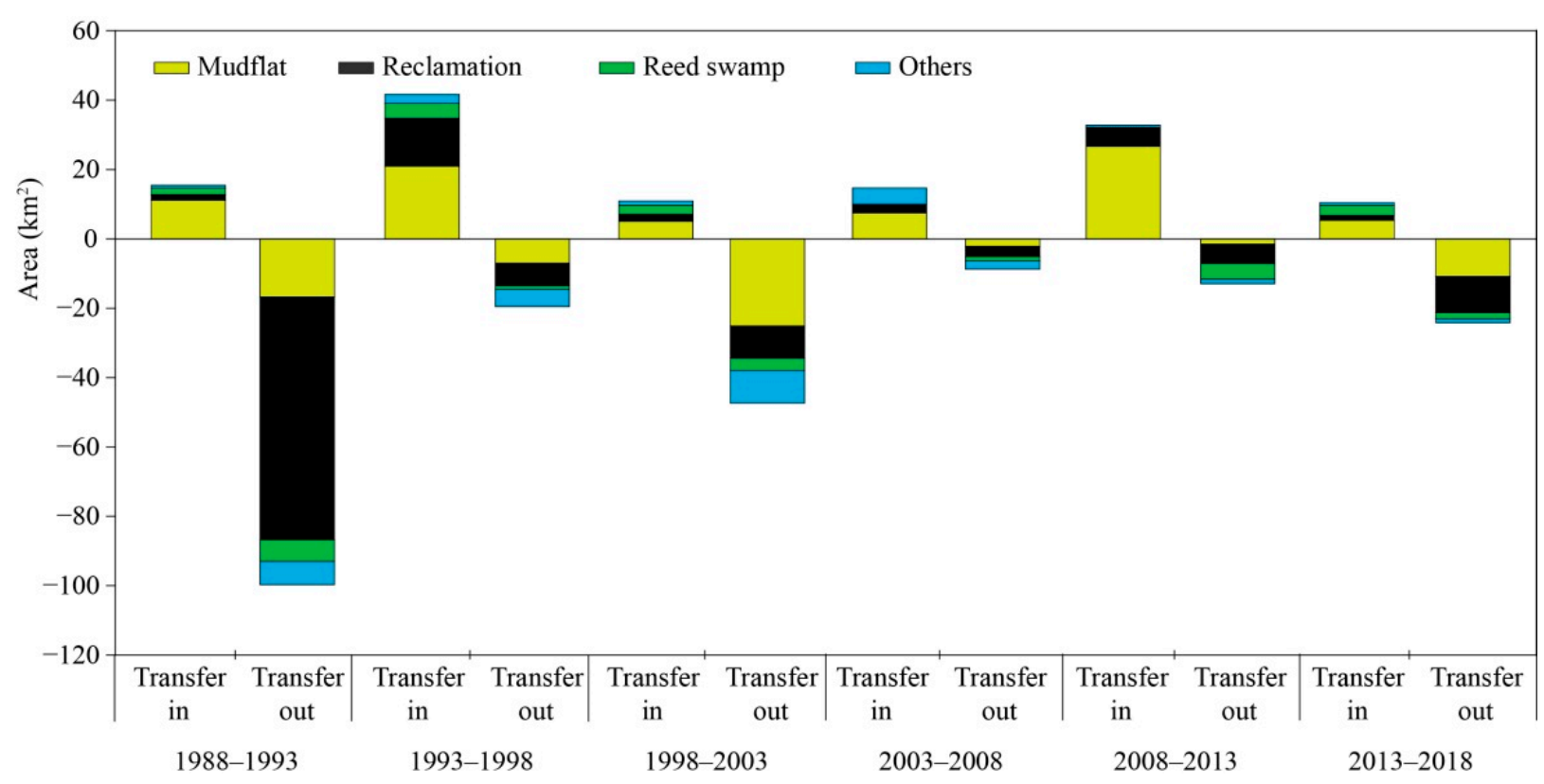

Figure 8. Land change between S. salsa saltmarsh area and other habitats near Liaodong Bay from 1988 to 2018.

Our study has revealed variation in the loss of $S$. salsa saltmarsh areas across different regions of the NYSC, which may be related to the differences in the conservation management capacities of different protected areas; the $S$. salsa saltmarsh area in Liaodong Bay was subject to an enormous 77\% decline, whereas in the Yellow River Delta wetland and the Guangli-Zhima estuarine wetland has declined by $52 \%$. Variation in land-use practices also contributes to these patterns of habitat loss; Liaodong Bay is the largest bay within the Yellow Sea and is nourished by several rivers, but in order to develop the local economy, a large area of $S$. salsa saltmarsh has been converted into aquaculture ponds, infrastructure such as roads, and reservoirs. Another area of great concern is the near complete loss of the S. salsa saltmarsh in Huludao city, Jingzhou City, Yingkou City, and eastern Panjing City. Even in the Liaohekou National Nature Reserve, the $S$. salsa saltmarsh has declined rapidly because of tourism development and the construction of oil production infrastructure, 
particularly during the period from 1988 to 1993 . In contrast, due to the conservation management of the Yellow River Delta National Nature Reserve, little reclamation occurred in this region except for in the Guangli-Zhima estuarine wetland.

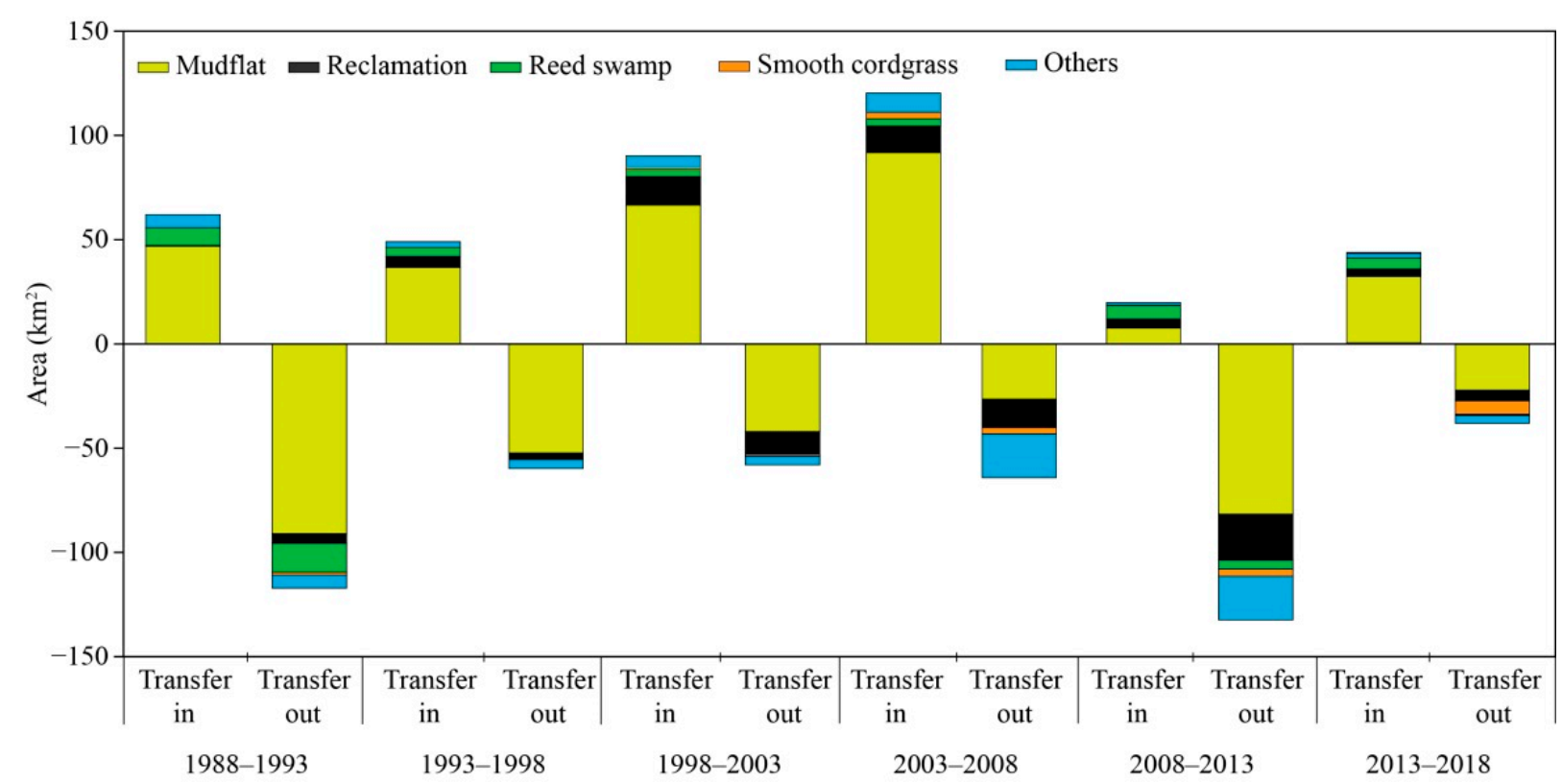

Figure 9. Land change between S. salsa saltmarsh area and other habitats near the Yellow River Delta wetland and the Guangli-Zhima estuarine wetland from 1988 to 2018.

Surprisingly, we found that the invasion by smooth cordgrass and natural succession has had limited impact on the decline of $S$. salsa saltmarsh areas near the NYSC. This contrasts with findings from the nearby Yancheng National Nature Reserve, where a large area of Suaeda was invaded by smooth cordgrass [31], which was initially introduced to control shoreline erosion and to promote the reclamation of China's coastal tidal flats in 1979 [4,32]. Significant areas of coastal wetlands have been invaded by the rapid expanding smooth cordgrass along the natural shoreline, which may dramatically change the ecological functions of the native coastal wetland landscape. For example, smooth cordgrass can rapidly proliferate to occupy large areas of mudflats, which could impact migratory shorebirds that strongly depend on these habitats as feeding grounds $[35,36]$. In recent years, there is some evidence to suggest that smooth cordgrass had expanded to the upper tidal flat and into the S. salsa saltmarsh in the north of China's coastal wetlands [32], and there are concerns that this may already be having an effect on the numerous endangered waterbird species that use these habitats.

After the Reform and Opening-up policy, China has become the second largest economy, which is part due to to rapid economic growth along its coastal region [2]. However, such rapid economic development would come at the inevitable expense of ecological security. During the past three decades, over $53 \%$ of coastal wetland areas have been lost due to land reclamation, developing aquaculture, and agriculture in order to promote economic development along the Yellow Sea [4]. Generally, S. salsa saltmarshes, which are located in the upper tidal flats, suffered the most extensive reclamation, which has been confirmed by this and two other previous studies [6,24]. Moreover, other factors (e.g., oil pollution, sea-level rise, lower runoff of river discharge) have prevented the growth and expansion of the S. salsa saltmarshes [28]. Fortunately, since the idea of "clear waters and green mountains are as good as mountains of gold and silver" advocated by Xi Jinping, the President of the People's Republic of China, and the strict ban on coastal wetland land reclamation since 2018 by the State Council of the People's Republic of China, numerous developments such as reclaiming land from the sea and aquaculture ponds have been pre- 
vented, leading to opportunities for habitat restoration efforts; for example, the abandoned aquaculture ponds, roads, and tourist facilities in Liaohekou National Nature Reserve have recently been restored to mudflats and $S$. salsa habitat, increasing the distribution region of S. salsa saltmarshes in this reserve (albeit slowly). However, illegal reclamation continues in the region, and further efforts are needed from the government to halt these and to provide greater funding for wetland restoration.

In summary, we quantified the spatial-temporal distribution and changes of $S$. salsa saltmarshes along the NYSC using Landsat long-time series images. We found that human land reclamation was the main reason for the loss and fragmentation of $S$. salsa saltmarshes from 1988 to 2018. Although different protection policies have been announced since the dramatic degradation of these vital coastal wetland ecosystems, which have made some significant progress regionally, urgent action is still needed to reverse these losses and to assess the ecological consequences, especially for the rapid loss of the $S$. salsa saltmarshes along the NYSC. Only two national nature reserves and a handful of provincial nature reserves are currently established along the NYSC [14,37]. Such a paucity of suitably sized and correctly situated protected areas along the NYSC may further accelerate the loss of this critical coastal wetland ecosystem and its biodiversity.

Author Contributions: D.L. and Z.Z.; conceived and designed the study. J.Z., Y.Z. and D.L.; performed experiment. J.Z. and Y.Z.; analyzed the data. J.Z. and D.L.; wrote the manuscript. J.Z., H.L., Z.Z. and D.L.; modified, edited, and finalized the manuscript. All authors reviewed and approved the manuscript. All authors have read and agreed to the published version of the manuscript.

Funding: This work was financially supported by the National Natural Science Foundation of China (No. 31911540468 and 31672316 to D.L.), the Natural Science Foundation of Liaoning Province of China (2019-MS-154 to D.L.), and the Non-profit Foundation of Marine Environment and Ecological Conservation of CNOOC (CF-MEEC/TR/2020-20 to Z.Z.).

Institutional Review Board Statement: Not applicable.

Informed Consent Statement: Not applicable.

Data Availability Statement: The data subsets used and/or analysed during this study are available from the corresponding author on request.

Acknowledgments: We thank the Liaohekou National Nature Reserve, the Yellow River Delta National Natural Reserve, Yu Bai, and Hang Zhang for their assistance with data collection in the field and Lei Cao and Jianqiang Li for the useful discussions about the manuscript. We thank the Landsat data supplied by the USGS, the Geospatial Data Cloud website, Google Earth, and Google Maps to provide analysis and data validation. We also thank two anonymous reviewers for their constructive comments.

Conflicts of Interest: The authors declare no conflict of interest.

\section{References}

1. Arkema, K.K.; Guannel, G.; Verutes, G.; Wood, S.A.; Guerry, A.D.; Ruckelshaus, M.; Kareiva, P.; Lacayo-Emery, M.; Silver, J.M. Coastal habitats shield people and property from sea-level rise and storms. Nat. Clim. Chang. 2013, 3, 913-918. [CrossRef]

2. Ma, Z.; Melville, D.S.; Liu, J.; Chen, Y.; Yang, H.; Ren, W.; Zhang, Z.; Piersma, T.; Li, B. Rethinking China's new great wall. Science 2014, 346, 912-914. [CrossRef]

3. Barbier, E.B.; Hacker, S.D.; Kennedy, C.; Koch, E.W.; Stier, A.; Silliman, B. The value of estuarine and coastal ecosystem services. Ecol. Monogr. 2011, 81, 169-193. [CrossRef]

4. Chen, Y.; Dong, J.; Xiao, X.; Ma, Z.; Tan, K.; Melville, D.; Li, B.; Lu, H.; Liu, J.; Liu, F. Effects of reclamation and natural changes on coastal wetlands bordering China's Yellow Sea from 1984 to 2015. Land Degrad. Dev. 2019, 30, 1533-1544. [CrossRef]

5. Murray, N.; Phinn, S.R.; DeWitt, M.; Ferrari, R.; Johnston, R.; Lyons, M.B.; Clinton, N.; Thau, D.; Fuller, R.A. The global distribution and trajectory of tidal flats. Nature 2018, 565, 222-225. [CrossRef] [PubMed]

6. Wang, Y.; Ji, Y.; Sun, Z.; Li, J.; Zhang, M.; Wu, G. Analysis of Suaeda heteroptera cover change and its hydrology driving factors in the Liao River Estuary wetlands, China. IOP Conf. Ser. Earth Environ. Sci. 2020, 467, 012150. [CrossRef]

7. Passeri, D.L.; Hagen, S.C.; Medeiros, S.C.; Bilskie, M.V.; Alizad, K.; Wang, D. The dynamic effects of sea level rise on low-gradient coastal landscapes: A review. Earth's Futur. 2015, 3, 159-181. [CrossRef] 
8. Lu, W.; Xiao, J.; Lei, W.; Du, J.; Li, Z.; Cong, P.; Hou, W.; Zhang, J.; Chen, L.; Zhang, Y.; et al. Human activities accelerated the degradation of saline seepweed red beaches by amplifying top-down and bottom-up forces. Ecosphere 2018, 9, e02352. [CrossRef]

9. Studds, C.E.; Kendall, B.E.; Murray, N.; Wilson, H.B.; Rogers, D.I.; Clemens, R.S.; Gosbell, K.; Hassell, C.J.; Jessop, R.; Melville, D.S.; et al. Rapid population decline in migratory shorebirds relying on Yellow Sea tidal mudflats as stopover sites. Nat. Commun. 2017, 8, 14895. [CrossRef]

10. Barter, M. Shorebirds of the Yellow Sea: Importance, Threats and Conservation Status; Wetlands International Global Series 9; International Wader Studies 12; Wetlands International: Canberra, Australia, 2002.

11. MacKinnon, J.; Verkuil, Y.I.; Murray, N. IUCN Situation Analysis on East and Southeast Asian Intertidal Habitats, with Particular Reference to the Yellow Sea (Including the Bohai Sea); Occasional Paper of the IUCN Species Survival Commission No. 47; IUCN: Gland, Switzerland; Cambridge, UK, 2012.

12. Bamford, M.; Watkins, D.; Bancroft, W.; Tishchler, G.; Wahl, J. Migratory Shorebirds of the East Asian-Australasian Flyway; Wetland International: Canberra, Australia, 2008.

13. China Coastal Waterbird Census Group; Bai, Q.; Chen, J.; Chen, Z.; Dong, G.; Dong, J.; Dong, W.; Fu, V.W.K.; Han, Y.; Lu, G.; et al. Identification of coastal wetlands of international importance for waterbirds: A review of China Coastal Waterbird Surveys 2005-2013. Avian Res. 2015, 6, 12. [CrossRef]

14. Ma, Z.; Chen, Y.; Melville, D.S.; Fan, J.; Liu, J.; Dong, J.; Tan, K.; Cheng, X.; Fuller, R.A.; Xiao, X.; et al. Changes in area and number of nature reserves in China. Conserv. Biol. 2019, 33, 1066-1075. [CrossRef]

15. UNESCO. Migratory Bird Sanctuaries along the Coast of Yellow Sea-Bohai Gulf of China (Phase I). Available online: https: //whc.unesco.org/en/list/1606/ (accessed on 13 November 2019).

16. Murray, N.; Clemens, R.S.; Phinn, S.R.; Possingham, H.; Fuller, R. Tracking the rapid loss of tidal wetlands in the Yellow Sea. Front. Ecol. Environ. 2014, 12, 267-272. [CrossRef]

17. Moores, N.; Rogers, D.I.; Rogers, K.; Hansbro, P. Reclamation of tidal flats and shorebird declines in Saemangeum and elsewhere in the Republic of Korea. Еmu 2016, 116, 136-146. [CrossRef]

18. Salman, A. Muddy coasts of the world: Processes, deposits and functions. J. Coast. Conserv. 2002, 8, 103. [CrossRef]

19. Peng, H.-B.; Anderson, G.Q.A.; Chang, Q.; Choi, C.-Y.; Chowdhury, S.U.; Clark, N.A.; Gan, X.; Hearn, R.D.; Li, J.; Lappo, E.G.; et al. The intertidal wetlands of southern Jiangsu Province, China-globally important for Spoon-billed Sandpipers and other threatened waterbirds, but facing multiple serious threats. Bird Conserv. Int. 2017, 27, 305-322. [CrossRef]

20. Choi, C.-Y.; Battley, P.; Potter, M.; Rogers, K.G.; Ma, Z. The importance of Yalu Jiang coastal wetland in the north Yellow Sea to Bar-tailed Godwits Limosa lapponica and Great Knots Calidris tenuirostris during northward migration. Bird Conserv. Int. 2014, 25, 53-70. [CrossRef]

21. Duan, H.; Xia, S.; Jackson, M.; Zhao, N.; Liu, Y.; Teng, J.; Meng, Z.; Yu, X.; Shi, J. Identifying new sites of significance to waterbirds conservation and their habitat modification in the Yellow and Bohai Seas in China. Glob. Ecol. Conserv. 2020, 22, e01031. [CrossRef]

22. Zhang, J.; Bai, Y.; Huang, Z.; Zhang, Z.; Li, D. Community composition and behavioral differences of migrating shorebirds between two habitats within a Suaeda salsa saltmarsh-mudflat wetland mosaics. Biodivers. Sci. 2021, 29, 351-360. [CrossRef]

23. Guan, B.; Yu, J.; Lu, Z.; Xie, W.; Chen, X.; Wang, X. The ecological effects of Suaeda salsa on repairing heavily degraded coastal saline-alkaline wetlands in the Yellow River Delta. Acta Ecol. Sin. 2011, 31, 4835-4840.

24. Tian, Y.; Luo, L.; Mao, D.; Wang, Z.; Li, L.; Liang, J. Using Landsat images to quantify different human threats to the Shuangtai Estuary Ramsar site, China. Ocean Coast. Manag. 2017, 135, 56-64. [CrossRef]

25. Li, D.; Liu, Y.; Sun, X.; Lloyd, H.; Zhu, S.; Zhang, S.; Wan, D.; Zhang, Z. Habitat-dependent changes in vigilance behaviour of Red-crowned Crane influenced by wildlife tourism. Sci. Rep. 2017, 7, 1-11. [CrossRef]

26. Li, D.; Zhang, J.; Chen, L.; Lloyd, H.; Zhang, Z. Burrow ambient temperature influences Helice crab activity and availability for migratory Red-crowned cranes Grus japonensis. Ecol. Evol. 2020, 10, 11523-11534. [CrossRef]

27. Li, D.; Chen, S.; Guan, L.; Lloyd, H.; Liu, Y.; Lv, J.; Zhang, Z. Patterns of waterbird community composition across a natural and restored wetland landscape mosaic, Yellow River Delta, China. Estuar. Coast. Shelf Sci. 2011, 91, 325-332. [CrossRef]

28. Lu, X.; Huang, Y.; Hong, J.; Zeng, D.; Yang, L. Spatial and temporal variations in wetland landscape patterns in the Yellow River Delta based on Landsat images. China Environ. Sci. 2018, 38, 4314-4324. [CrossRef]

29. Chen, K. Study on Migratory Waterbirds and Wetlands in the Yellow Sea; China Forestry Publish Press: Beijing, China, 2006.

30. Xing, Y.; Xing, J. Some taxonomy errors in studies on China Suaeda. Mar. Sci. 2019, 43, 97-102. [CrossRef]

31. Fang, R.; Shen, Y. Effects of Coast Beach Reclamation on the Change of Landscape Pattern and Its Spatial Centroids: A Case Study in Coastal Wetland of Part of Yancheng National Natural Reserve. J. Nat. Resour. 2015, 30, 772-783. [CrossRef]

32. Liu, M.; Mao, D.; Wang, Z.; Li, L.; Man, W.; Jia, M.; Ren, C.; Zhang, Y. Rapid Invasion of Spartina alterniflora in the Coastal Zone of Mainland China: New Observations from Landsat OLI Images. Remote Sens. 2018, 10, 1933. [CrossRef]

33. Silva, R.; Martínez, M.; Van Tussenbroek, B.; Guzmán-Rodríguez, L.; Mendoza, E.; López-Portillo, J. A Framework to Manage Coastal Squeeze. Sustainability 2020, 12, 10610. [CrossRef]

34. Wang, H.; Yang, Z.; Saito, Y.; Liu, P.; Sun, X.; Wang, Y. Stepwise decreases of the Huanghe (Yellow River) sediment load (1950-2005): Impacts of climate change and human activities. Glob. Planet. Chang. 2007, 57, 331-354. [CrossRef]

35. Cui, B.-S.; He, Q.; An, Y. Spartina alterniflora invasions and effects on crab communities in a western Pacific estuary. Ecol. Eng. 2011, 37, 1920-1924. [CrossRef] 
36. Liu, C.; Jiang, H.; Hou, Y.; Zhang, S.; Su, L.; Li, X.; Pan, X.; Wen, Z. Habitat Changes for Breeding Waterbirds in Yancheng National Nature Reserve, China: A Remote Sensing Study. Wetlands 2010, 30, 879-888. [CrossRef]

37. Mao, D.; Wang, Z.; Wang, Y.; Choi, C.-Y.; Jia, M.; Jackson, M.V.; Fuller, R.A. Remote Observations in China's Ramsar Sites: Wetland Dynamics, Anthropogenic Threats, and Implications for Sustainable Development Goals. J. Remote Sens. 2021, $2021,1-13$. [CrossRef] 